\title{
Athletic performance, training characteristics, and orthopedic indications in junior tennis Davis
}

Received: 22 April 2019

For correspondence:

Janina Fett

Janina.fett@rub.de

\section{Cup players}

Janina Fett, Alexander Ulbricht, Thimo Wiewelhove \& Alexander Ferrauti

Department of Training and Exercise Science, Faculty of Sport Science, Ruhr University Bochum, Bochum, Germany

Please cite this postprint as: Fett, J., Ulbricht, A., Wiewelhove, T. \& Ferrauti, A. (2020). Athletic performance, training characteristics, and orthopedic indications in junior tennis Davis Cup players. SportRxiv https://doi.org/10.31236/osf.io/2nue7

Postprint License: Creative Commons Attribution-NonCommercial-NoDerivatives 4.0 (CC BY-NC-ND 4.0) Journal Article: Fett, J., Ulbricht, A., Wiewelhove, T. \& Ferrauti, A. (2017). Athletic performance, training characteristics, and orthopedic indications in junior tennis Davis Cup players. International Journal of Sports Science \& Coaching, 12(1), 119-129. https://doi.org/10.1177/1747954116684393

\section{ABSTRACT}

Our study aimed to examine athletics, training characteristics, and prevalence of musculoskeletal symptoms of male junior tennis Davis Cup players (DC) in comparison with their regional counterparts, as well as to evaluate the impact of age and performance level on training characteristics. Twelve junior DC (male) and two samples of regional squad players (RS1 $n=60$ males, $n=47$ females; RS2 $n=59$ males) participated in a physical testing, an interview for data evaluation on training characteristics, and a questionnaire survey of orthopedic injury frequency. Results indicate higher physical performance levels (effect size (ES) 0.75-1.26) and training volumes in DC (ES 1.23-1.66). In DC, significant relationships were found between total training volume and tennis ranking $(r=-0.78)$, age and physical training volume $(r=0.82)$, and age and total training volume $(r=0.62)$. Injury frequencies showed moderate to high prevalence with no differences $(p>0.05)$ between DC and RS. Given the demands of elite tennis and the important role of service in the modern game, more efforts are necessary to develop training prescription for both performance enhancement and prevention strategies.

Keywords: Age, orthopaedic assessment, physical fitness, sports injury prevention, tennis serve, training volume, youth sport 


\section{INTRODUCTION}

The modern game of tennis has evolved from a primary technical sport to the current explosive sport becoming increasingly dynamic and faster based on strength, speed, and power with higher stroke and serve velocities leading the service game to being a key factor in game success. ${ }^{1-3}$ Consequently, tennis is a complex sport requiring technical, tactical, psychological, and highlevel physical skills to be successful. ${ }^{1,3}$

While technical skills are predominant factors, ${ }^{4}$ the importance of the athletes' physical fitness, including a complex profile of speed, agility, and power combined with medium to high aerobic and anaerobic capacity, is also well accepted. ${ }^{3,5}$ Functional links observed between muscular strength in the dominant upper and lower limbs and ranking position in competitive tennis players reinforce the notion that physical attributes have a strong influence on tennis performance and might be important determinants for successful participation in elite tennis. ${ }^{6-8}$ Nevertheless, it is debatable whether the impact of fitness on the complex tennis performance is crucial to detect differences in performance levels. With regard to this issue, there is a lack of information for tennis analyzing the effect of performance level on athletic characteristics.

Due to the intense demands of the modern tennis game, an increased strain on players in training and competition exists. Therefore, in order to be competitive, players must devote a great amount of time to improving their tennis skills and high demands of training workloads must be tolerated. A training workload of 15-20 hours per week (h/wk) of technical and tactical training is recommended to achieve high competitive levels, not including a further conditioning program.,10 In addition, even though the important role of physical skills for tennis performance is known, it seems that only a minimum of specific physical training sessions can be programmed per week. This might be due to a lack of proposal time. ${ }^{10}$ To date, very little information has been reported about the actual total training workload, including time spent for fitness improvement of the players, especially of young athletes, their distribution of training contents, and if there is a functional link to tennis performance. Further, it is reasonable to assume that players of a higher performance level would outperform players of a lower level with respect to training characteristics in both quality and quantity. Yet, there is no data comparing these items in elite and sub-elite players.

In addition, during the last few years there has been a subsequent steady rise in the number of injuries in tennis, most commonly overuse injuries. ${ }^{11}$ The considerable high demands of elite tennis with high training volumes, full tournament schedules from an early age, as well as the repetitive nature of high-loading movement patterns (i.e., exertion of the serve motion, quick starts, stops, and changes of direction) along with the use of artificial surfaces, lead to high stress which may in turn result in an increased injury potential. 6,12,13 In particular, the stroke production generates high repetitive forces; the serve has been reported to be the most traumatic and exhausting skill on the upper extremity. ${ }^{13,14}$ Consequently, the tennis serve could be described as a dominant limiting performance factor, accompanied by a higher risk of 
developing musculoskeletal disorders. ${ }^{11}$ Nevertheless, there is less information about injury frequency in elite German junior players, especially regarding injuries directly related to the serve performance and specifically to different performance levels.

Thus, the aim of the study was to describe and examine athletic performance, training characteristics and prevalence of musculoskeletal injuries of junior tennis Davis Cup players (DC) in comparison with their regional counterparts (regional squads), as well as to evaluate the impact of age and performance level on given training characteristics.

\section{METHODS}

\section{Subjects}

Twelve nationally ranked male junior DC and two samples of junior squad players of the regional federations (RS1, $n=60$ males, $n=47$ females; $R S 2, n=59$ males) participated in this study. Anthropometric data are shown in Table 1. All players were familiar with the test procedures and the testing surroundings. Written informed consent was obtained before participation. The study was approved by the local ethics committee and conformed to the recommendations of the Declaration of Helsinki.

\section{Experimental set up}

This study examined athletic performance, training workloads, and orthopedic injuries of junior $D C$ in comparison with their regional counterparts. The experimental design was divided into different parts (Table 1):

(1) Athletic performance measurements: For assessment of athletic performance, subjects (DC, RS2) performed the German Physical Condition Tennis Test. ${ }^{10}$ Data of DC were obtained during a training workshop in laboratories at the Department of Training and Exercise Science at Ruhr University Bochum, while data for regional squads were gathered at the players' respective federation base over a three-week period of time.

Table I. Individual characteristics of the players and classification to the experimental set up. Data are presented as mean \pm SD.

\begin{tabular}{|c|c|c|c|c|c|c|c|}
\hline & \multirow[b]{2}{*}{$N$} & \multirow[b]{2}{*}{ Age (year) } & \multirow[b]{2}{*}{ Weight $(\mathrm{kg})$} & \multirow[b]{2}{*}{ Height (cm) } & \multicolumn{3}{|c|}{ Participation in } \\
\hline & & & & & Fitness test & $\begin{array}{l}\text { Interview } \\
\text { (training) }\end{array}$ & $\begin{array}{l}\text { Orthopedic } \\
\text { questionnaire }\end{array}$ \\
\hline Davis Cup players (m) & 12 & $15.6 \pm 1.1$ & $69.8 \pm 11.7$ & $180.7 \pm 9.6$ & $x$ & $x$ & $x$ \\
\hline $\mathrm{RS} 2(\mathrm{~m})$ & 59 & $15.2 \pm 0.6$ & $62.4 \pm 8.7$ & $176.3 \pm 7.7$ & $x$ & $x$ & \\
\hline \multicolumn{8}{|l|}{ RSI } \\
\hline Male & 60 & $14.9 \pm 2.5$ & $58.6 \pm 15.4$ & $171.2 \pm 13.9$ & & & $x$ \\
\hline Female & 47 & $14.6 \pm 2.1$ & $54.1 \pm 10.6$ & $166.1 \pm 10.9$ & & & $x$ \\
\hline
\end{tabular}

f: female; m: male. 
(2) Training characteristics: All athletes (DC, RS2) participated in an interview for data collection on training characteristics, respectively at the Department of Training and Exercise Science and at the regional federation base.

(3) Orthopedic assessment: To obtain an orthopedic status (orthopedic injury prevalence), a selfreported questionnaire was used in total of 107 regional squad players (RS1) as well as in DC $(n=12)$.

\section{Athletic performance and anthropometric measurements}

Physical performance was assessed using the standardized fitness test battery of the German Tennis Federation. ${ }^{10}$ Using the German Physical Condition Tennis Test Protocol, an assessment of athletic performance can be conducted by norm values and percentiles as described by Ulbricht et al. ${ }^{10}$ and Fernandez-Fernandez et al. ${ }^{15}$ The percentiles can be used to obtain norm referenced interpretations of the performed fitness score within a distribution consisting of scores from a comparable section. ${ }^{16}$ By means of this fitness-testing concept, individual profiles of the players with their respective strengths and weaknesses in comparison with their peers could be obtained. ${ }^{10}$ Physical performance tests were conducted in an indoor tennis court (Rebound Ace surface) and began after a 15-minute individual warm-up, consisting of lowintensity forward, sideways, and backward running, acceleration runs, hopping exercises, and jumps of increasing intensity. ${ }^{10}$

Anthropometry and maturity status.

Testing sessions started with a measurement of the athlete's body dimensions. Anthropometrical measurements included body height, body mass, and sitting height. Athletes' body height was obtained with a fixed stadiometer $( \pm 0.1 \mathrm{~cm}$, Holtain Ltd., Crosswell, UK) and sitting height with a purpose-built table $( \pm 0.1 \mathrm{~cm}$, Holtain Ltd., Crosswell, UK) to the nearest millimeter. Body mass to the nearest $0.1 \mathrm{~kg}$ was recorded with a digital balance $( \pm 0.1 \mathrm{~kg}$, ADE Electronic Column Scales, Hamburg, Germany). ${ }^{10}$ In addition, leg length was calculated by subtracting sitting height from body height. ${ }^{17}$ Status of maturity was calculated according to the biological age of maturity of each individual as described by Mirwald et al. ${ }^{17}$ The age at peak height velocity is a commonly used indicator of somatic maturity representing the time of the fastest rate of growth in stature during adolescence. ${ }^{17,18}$ By subtracting the chronological age at the time of measuring from the chronological peak-velocity age, the biological age of maturity (in years) was estimated. ${ }^{17-19}$

Service velocity.

First serve velocity was measured using a radar gun (Stalker Professional Sports Radar, Radar Sales, Plymouth, MN). The radar was located on the center of the baseline, $4 \mathrm{~m}$ behind the server, 
aligned with the height of $3 \mathrm{~m}$, and pointing down the center of the court. Right-handed participants served from the deuce court and left-handed players from the ad court. After a brief warm-up consisting of serves with increasing velocity, eight first serves were performed. The average service speed was used for further analysis. ${ }^{10}$

Medicine ball throws (MBT). Overhead, forehand, and backhand.

Players were required to perform an overhead, a forehand, and a backhand MBT. ${ }^{15}$ Holding a 2$\mathrm{kg}$ medicine ball with both hands, the players stood on a line facing the throwing direction. After the ball was brought back behind the head, it was thrown forward as far as possible. Players were allowed to cross the line after tossing the ball. For performing the fore- and backhand MBT, players stood sideways on the starting line and simulated a forehand/backhand stroke. Distance was measured between the starting line and the point where the ball landed. Each player performed two repetitions on each side, and the best performance was recorded to the nearest $5 \mathrm{~cm}^{10}$

\section{Grip strength.}

Maximal hand grip strength was measured with a hydraulic hand dynamometer with a handle

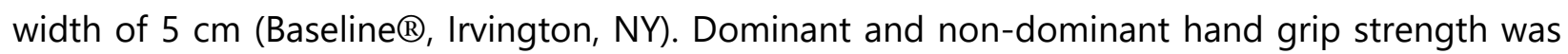
assessed in a standing position, elbow extended, and the arm positioned with the dynamometer parallel to the subject's side. Participants were asked to perform a maximal voluntary contraction, squeezing the dynamometer as hard as possible for three seconds. ${ }^{10,20}$ The maximum force (in kilograms) achieved among two trials for each side was recorded.

\section{Push-up test.}

All subjects were required to perform as many push-ups as possible. ${ }^{21}$ For their starting position, the players placed their hands approximately 0.1-0.2 $\mathrm{m}$ wider than shoulder width while maintaining a horizontal spinal position. After diffracting the elbows, in order to lower the body until the chest was approximately $5 \mathrm{~cm}$ from the ground, subjects extended the elbows thereby returning to the initial position. ${ }^{10}$ Speed of movement was controlled with an audio pacer set to $2 \mathrm{~s}$ for each repetition, with $1 \mathrm{~s}$ for concentric and $1 \mathrm{~s}$ for eccentric movement. The maximum repetition number performed with an appropriate technique was obtained with a maximum number set to 50 .

\section{Back extension test.}

For the back extension test, players lay on a mat in a downward position holding $1 \mathrm{~kg}$ dumbbells in their hands with the elbows bent at right angles and the lower limbs remaining on the ground. While maintaining an upright position of the upper body without contact with the ground, players were asked to extend their elbows before returning to the initial position. Speed 
of movement was controlled with an audio pacer set to $2 \mathrm{~s}$ for each repetition, with $1 \mathrm{~s}$ for extending and $1 \mathrm{~s}$ for bending the elbows. The maximum repetition number performed with an appropriate technique was obtained with a maximum number set to 50 .

\section{0-m linear sprint.}

Time of a $20-\mathrm{m}$ sprint in a straight line was measured by means of double-beam photocell gates placed 1.0m above ground level (Sportronic TS01-R04, Leutenbach-Nellmersbach, Germany). Split times were recorded for $5 \mathrm{~m}$ and $10 \mathrm{~m}$. Players were asked to start without a starting signal from an individually chosen standing position, $50 \mathrm{~cm}$ behind the first photocell gate, thus triggering a digital timer. All subjects performed two maximal 20-m dashes interspersed with three minutes of passive recovery, and the fastest trial was recorded. ${ }^{10}$

\section{Countermovement jumps (CMJ).}

Double-leg vertical jumps without arm swing (i.e., with the hands on hips) were performed on a contact platform (Haynl Elektronik, Schönebeck, Germany) according to Bosco et al. ${ }^{22}$ Each player performed two maximal CMJs interspersed with $45 \mathrm{~s}$ recovery, and the best height determined by flight time was recorded.

\section{Hit \& Turn Tennis Test.}

The Hit \& Turn Tennis Test is an acoustically controlled progressive on-court endurance test for tennis players. ${ }^{23}$ The test, consisting of 20 levels, involves specific movement patterns along the baseline (i.e., sidesteps and running) combined with forehand and backhand stroke simulations at the doubles court corner. There is a decreasing time span, i.e., $0.1 \mathrm{~s}$ per level, between the forehand and backhand strokes starting from $4.9 \mathrm{~s}$ (level 1) and reducing to $3.0 \mathrm{~s}$ (level 20). The duration of each test level is about 47-50 s, including 12-16 strokes with a rest period of $10 \mathrm{~s}$ after each level. For optional blood sampling, a longer break of $20 \mathrm{~s}$ is established after levels 4, 8, 12, and 16. Each test level starts from an initial position, where the players stand with their rackets in a frontal position at the middle of the baseline. Upon hearing a signal, the players turn sideways and run to the prescribed backhand and forehand corner, making their shot and return to the middle of the court using sidesteps or crossover steps (while looking at the net). When passing the middle of the baseline again, players turn sideways and continue to run to the opponent's opposite corner. The test was accomplished when the players failed to reach the corners in time or were no longer able to fulfill the prescribed movement patterns. The maximal completed test level was then recorded. Equations were determined and evaluated describing the relation between test levels and $\mathrm{VO}_{2}$, which enables the estimation of $\mathrm{VO}_{2 \text { max. }}{ }^{23}$

\section{Shoulder flexibility.}

Shoulder flexibility was measured using the shoulder mobility test of the Functional Movement 
Screen (FMS) according to Cook et al. ${ }^{24}$ After making a fist with each hand, players were required to assume a maximally adducted and internally rotated position with one shoulder and a maximally abducted and externally rotated position with the other one. ${ }^{24}$ The distance between both fists was measured. Each player was tested bilaterally and started with the dominant arm in an internally rotated position.

\section{Stand-and-reach test.}

The stand-and-reach test was used to measure flexibility of the hamstrings and lower back. It was defined as having positive values when the players' fingertips reached over the standing line $( \pm 0.5 \mathrm{~cm})$. Each player performed one trial.

\section{Training documentation}

Data collection on training characteristics for each participant was undertaken during a standardized interview, the contents of which were determined by several experts in the field of tennis coaching and science. The isolated workloads of tennis training (TT), physical training, and of additional sport activities performed were retained for a normal training week (out of competition phase) and recorded in hours per week. Total training volume and the ratio of TT to physical conditioning (PT) was calculated. In addition, training history (years of practice, age of start playing tennis (years)), the organization form of tennis training (relation player: coach; 1:1, $2: 1,3: 1$, and $4: 1$ in percentage), and the distribution of training contents (warm-up, small-sided practice, technique, match training, and on-court physical training in percentage) throughout TT were obtained.

\section{Orthopedic injury prevalence}

Prevalence of musculoskeletal symptoms (MS) was recorded by a questionnaire developed in accordance with the standardized and validated Nordic Questionnaire. ${ }^{25}$ The applied questionnaire includes (1) questions of limitations in the region of neck, shoulder, elbow, hand/wrist, thoracic spine, lumbar spine, hip, knee, and ankle/feet throughout the whole tennis career; (2) questions of limitations in upper extremities (shoulder, elbow, and hand/wrist) during the previous 12 months and in accordance with defined stroke performance (forehand, backhand, and serve); and (3) a pain score for the region of shoulder, elbow, and hand/wrist while performing the tennis serve. For pain severity measurement, the Numeric Pain Rating Scale was utilized, using ratings ranging from " 0 " indicating "no pain" up to " 10 " indicating the "worst possible pain." 26 Non-standard questions were thoroughly pilot tested. Due to the fact that injury patterns are more likely to be sport than gender specific, it was decided to forego dividing the sample into males and females. 


\section{Statistics}

All data are presented as mean values and standard deviations $( \pm \mathrm{SD})$. Independent sample $t$ tests were used to determine mean differences between junior DC and regional squads in anthropometric and physical performance as well as training characteristics. Further, the standardized difference or ES of changes in each parameter between the two groups was calculated using the pooled standard deviation. Threshold values for Cohen ES statistic were $<0.2$ (small), 0.5 (moderate), and >0.8 (large). ${ }^{27}$ Injury prevalence between groups was compared using chi-square statistics. For analyzing the correlation between training volume and age, as well as athletic performance, the Pearson product-moment correlation coefficient ( $r$ ) was used. Spearman's rank correlation coefficient was calculated between training volume and tennis performance (i.e., national youth ranking). The magnitude of correlation was classified as trivial $(0-0.1)$, small $(0.1-0.3)$, moderate $(0.3-0.5)$, large $(0.5-0.7)$, very large $(0.7-0.9)$, nearly perfect (0.9), and perfect (1.0). The $p \leq 0.05$ criterion was used to constitute statistical significance. Data analyses were performed using the SPSS statistical software package (version 18, SPSS Inc., Chicago, IL, USA) and Open Office (version 3.2.1; Oracle).

\section{RESULTS}

Mean values $( \pm S D)$ of athletic performance are presented in Table 2. Significant differences between DC and RS $(p<0.05)$ were found in shoulder flexibility (ES 0.85), CMJ (ES 0.75), back extension (ES 0.83), grip strength (ES 1.08), serve velocity (ES 1.26), MBT forehand (ES 1.04), and MBT backhand (ES 0.75), with the junior DC showing a better performance.

Table 3 shows mean and SD for training volume, training history, and training organization form. Junior DC start playing tennis at the age of 6.4 years $( \pm 1.0)$, have a training experience of $8.9( \pm 1.0)$ years, and a total training volume of $22.7( \pm 6.8) \mathrm{h} / \mathrm{wk}$. Training workload, match participation, and the organization form differed significantly between DC and RS $(p<0.05)$ with higher training volumes and lower percentages of group-based training sessions in DC (TT: ES 1.38; PT: ES 1.23; total training: ES 1.66; organization form 3:1: ES 0.53, organization form 4:1: ES 0.69).

Statistically significant relationships were found between total training volume and tennis performance $(r=-0.78, p<0.01)$, age and physical training volume $(r=0.82, p<0.01)$, and age and total training volume $(r=0.62, p<0.05)$, whereas no relation was found between age and volume of tennis training $(p>0.05)$. Moreover, volume of physical training and several athletic measurements including grip strength, MBT overhead, and MBT backhand $(r=0.62-0.65, p<0.05)$ showed significant correlations (Table 4). 
Table 2. Athletic performance of junior Davis-Cup players $(n=12)$ in comparison with regional squad players $(n=59)$.

\begin{tabular}{|c|c|c|c|c|c|}
\hline Qualities & Measurements & $\begin{array}{l}\text { Mean } \pm \text { SD } \\
\text { (Percentile value \%) } \\
\text { DC }\end{array}$ & $\begin{array}{l}\text { Mean } \pm \text { SD } \\
\text { (Percentile value \%) } \\
\text { RS }\end{array}$ & Diff. & ES $(90 \% \mathrm{Cl})$ \\
\hline \multirow[t]{5}{*}{ Anthro pometry } & Chronological age (years) & $15.60 \pm 1.14$ & $15.16 \pm 0.55$ & $0.44^{*}$ & $0.63(0.10 ; 1.16)$ \\
\hline & APHV (years) & $13.66 \pm 0.57$ & $13.97 \pm 0.60$ & -0.32 & $0.52(-1.05 ; 0.01)$ \\
\hline & YTPHV (years) & $1.94 \pm 1.28$ & $1.20 \pm 0.80$ & $0.75^{*}$ & $0.83(0.29 ; 1.36)$ \\
\hline & Height (cm) & $180.7 \pm 9.6(58.0)$ & $\mid 76.3 \pm 7.7(48.4)$ & 4.41 & $0.54(0.02 ; 1.07)$ \\
\hline & Weight (kg) & $69.8 \pm 11.7(59.2)$ & $62.4 \pm 8.7(43.5)$ & $7.42^{*}$ & $0.80(0.26 ; 1.33)$ \\
\hline \multirow[t]{3}{*}{ Flexibility } & Stand and reach test $(\mathrm{cm})$ & $7.6 \pm 6.2(60.8)$ & $6.2 \pm 10.0(52.5)$ & 1.43 & $0.15(-0.37 ; 0.67)$ \\
\hline & Shoulder flexibility D (cm) & $16.2 \pm 6.0$ & $19.7 \pm 7.3$ & -3.56 & $0.49(-1.02 ; 0.03)$ \\
\hline & Shoulder flexibility ND (cm) & $19.2 \pm 5.7$ & $14.0 \pm 6.0$ & $5.13^{*}$ & $0.85(0.32 ; 1.39)$ \\
\hline \multirow[t]{3}{*}{ Strength } & Grip strength D (kg) & $55.2 \pm 11.2(84.6)$ & $44.7 \pm 9.2(57.3)$ & $10.42^{*}$ & $1.08(0.54 ; 1.62)$ \\
\hline & Push up $(\mathrm{N})$ & $24.5 \pm 7.1(51.4)$ & $21.7 \pm 6.4(42.3)$ & 2.85 & $0.43(-0.09 ; 0.96)$ \\
\hline & Back extension (N) & $39.5 \pm 9.0(85.9)$ & $30.6 \pm 10.9(68.2)$ & $8.91 *$ & $0.83(0.29 ; 1.36)$ \\
\hline \multirow[t]{2}{*}{ Speed } & $10 \mathrm{~m}(\mathrm{~s})$ & $1.77 \pm 0.09(67.5)$ & $1.81 \pm 0.12(55.8)$ & -0.05 & $0.39(-0.91 ; 0.14)$ \\
\hline & $20 \mathrm{~m}(\mathrm{~s})$ & $3.11 \pm 0.14(60.8)$ & $3.18 \pm 0.13(57.7)$ & -0.07 & $0.51(-1.04 ; 0.01$ \\
\hline Jump & CMJ $(\mathrm{cm})$ & $40.7 \pm 4.5(63.3)$ & $37.6 \pm 4.1(52.3)$ & $3.16 *$ & $0.75(0.22 ; 1.28)$ \\
\hline \multirow[t]{4}{*}{ Upper body power } & MBT OH $(\mathrm{cm})$ & $1|5| .7 \pm 208.4(74.2)$ & $1065.5 \pm 150.5(71.2)$ & 86.15 & $0.53(0.00 ; 1.05)$ \\
\hline & MBT FH $(\mathrm{cm})$ & $1456.7 \pm 181.3(79.2)$ & $1281.9 \pm 163.7(60.5)$ & $174.77^{*}$ & $1.04(0.50 ; 1.58)$ \\
\hline & MBT BH $(\mathrm{cm})$ & $137 \mid .7 \pm 200.0(79.2)$ & $\mid 233.1 \pm 177.8(61.0)$ & $138.56^{*}$ & $0.75(0.22 ; 1.29)$ \\
\hline & Serve velocity $(\mathrm{km} / \mathrm{h})$ & $179.0 \pm 10.5(78.3)$ & $164.9 \pm 11.2(48.3)$ & $14.12^{*}$ & $\mathrm{I} .26(0.7 \mathrm{I} ; \mathrm{I} .8 \mathrm{I})$ \\
\hline Endurance & $\mathrm{VO}_{2 \max }$ estimate $(\mathrm{ml} / \mathrm{min} / \mathrm{kg})$ & $61.6 \pm 2.9(55.0)$ & $61.4 \pm 2.7(52.7)$ & 0.22 & $0.08(-0.44 ; 0.60)$ \\
\hline
\end{tabular}

APHV: estimated age at peak height velocity; BH: backhand; CMJ: counter movement jump; Diff.: difference; D: dominant hand; DC: Davis Cup players; ES: effect size; FH: forehand; $90 \%$ Cl: $90 \%$ confidence intervals; MBT: medicine ball throw; ND: non-dominant hand; OH: overhead; RS: regional squad players; YTPHV: estimated age from/to peak height velocity. $* p<0.05$ for differences between DC and RS.

Table 3. Training characteristics of junior Davis Cup players in comparison with regional squad players (mean \pm SD).

\begin{tabular}{|c|c|c|c|c|c|}
\hline Qualities & & $\begin{array}{l}\text { Mean } \pm \text { SD } \\
\text { DC }\end{array}$ & $\begin{array}{l}\text { Mean } \pm S D \\
\text { RS }\end{array}$ & Difference & $\mathrm{ES}(90 \% \mathrm{Cl})$ \\
\hline \multirow[t]{2}{*}{ Training history } & Years of practice (years) & $8.9 \pm 1.0$ & $8.9 \pm 2.3$ & 0.0 & $0.07(-0.59 ; 0.45)$ \\
\hline & Start playing tennis (years) & $6.4 \pm 1.0$ & $6.6 \pm 2.2$ & -0.2 & $0.01(-0.53 ; 0.5 \mathrm{I})$ \\
\hline \multirow[t]{6}{*}{ Training volume } & Tennis training $(\mathrm{h} / \mathrm{wk})$ & $15.1 \pm 4.3$ & $9.8 \pm 3.7$ & $5.3^{*}$ & $1.38(0.82 ; 1.93)$ \\
\hline & Physical training (h/wk) & $7.6 \pm 3.7$ & $4.5 \pm 2.2$ & $3.1^{*}$ & $1.23(0.68 ; 1.77)$ \\
\hline & Total training (h/wk) & $22.7 \pm 6.8$ & $14.4 \pm 4.5$ & $8.3^{*}$ & $1.66(1.09 ; 2.23)$ \\
\hline & Other sports $(\mathrm{h} / \mathrm{wk})$ & $1.8 \pm 0.7$ & $2.0 \pm 0.9$ & -0.2 & $0.23(-0.75 ; 0.29)$ \\
\hline & Ratio TT/PT & $2.5 \pm 1.5$ & $2.7 \pm 1.7$ & -0.2 & $0.12(-0.64 ; 0.40)$ \\
\hline & Matches single (n) & $75.6 \pm 12.5$ & $57.2 \pm 18.7$ & $18.4^{*}$ & $1.02(0.48 ; 1.56)$ \\
\hline Organization form & Training I:I (\%) & $38.4 \pm 31.6$ & $19.1 \pm 30.6$ & 19.3 & $0.62(0.09 ; 1.15)$ \\
\hline \multirow[t]{3}{*}{ Players: Coach } & Training 2:1 (\%) & $45.9 \pm 36.6$ & $29.7 \pm 38.8$ & 16.2 & $0.42(-0.11 ; 0.94)$ \\
\hline & Training 3:1 (\%) & $6.3 \pm 8.8$ & $19.2 \pm 25.9$ & $-12.9 *$ & $0.53(-1.06 ;-0.01)$ \\
\hline & Training 4:1 (\%) & $9.4 \pm 16.2$ & $31.9 \pm 34.5$ & $-22.5^{*}$ & $0.69(-1.22 ;-0.16)$ \\
\hline
\end{tabular}

DC: Davis Cup players; RS: regional squad players; PT: physical training; TT: tennis training. $* p<0.05$ for differences between DC and RS. 
Table 4. Correlations between training characteristics, age, and tennis performance in junior Davis Cup players.

\begin{tabular}{lcl}
\hline Item & $R$ & $P$ \\
\hline Statistical relation between total training volume and tennis \\
performance \\
$\begin{array}{l}\text { a } \\
\text { Tennis performance (ranking) }\end{array}$ & -0.78 & 0.003 \\
Statistical relation between age and training volume & \\
Volume physical training & 0.82 & 0.002 \\
Volume tennis training & 0.28 & $\mathrm{NS}$ \\
Volume total training & 0.62 & 0.030 \\
Ratio TT/PT & -0.80 & 0.003 \\
Statistical relation between volume of physical training & \\
and athletic performance & & \\
Grip strength & 0.64 & 0.03 \\
Medicine ball throw OV & 0.62 & 0.04 \\
Medicine ball throw BH & 0.65 & 0.03 \\
\hline
\end{tabular}

BH: backhand; OV: overhead.

${ }^{a}$ Spearman's $\rho$.

'Pearson's product-moment correlation coefficient.
Table 5. Prevalence of musculoskeletal symptoms in DC and RS.

\begin{tabular}{lll}
\hline Injury location & RS Prevalence (\%) & DC Prevalence (\%) \\
\hline Knee & 54 & 79 \\
Shoulder & 50 & 67 \\
Hand/wrist & 45 & 56 \\
Lumbar spine & 45 & 67 \\
Ankle/feet & 40 & 44 \\
Hip & 33 & 56 \\
Neck & 28 & 56 \\
Elbow & 25 & 22 \\
Thoracic spine & 22 & 56 \\
\hline
\end{tabular}

$p>0.05$ for analysis between DC and RS. DC: Davis Cup players; RS: regional squad players.

Data of injury frequencies depending on prescribed body locations and time modalities are shown in Tables 5 and 6 . Analysis of injury prevalence regarding performance level showed no differences $(p>0.05)$ in any body location. In junior squad players, the knee and the shoulder are the body areas where injuries occur most frequently. Reported 12-month prevalence of MS concerning the upper extremities revealed the highest scores for shoulder (RS 32\%, DC 44\%) followed by the hand (RS 25\%, DC 33\%), and elbow (RS 19\%, DC 0\%); these discomforts are mostly connected to the serve performance (i.e., shoulder and elbow).

Table 6. Upper extremity injury rate throughout the last 12 months in DC and RS.

\begin{tabular}{|c|c|c|c|c|c|c|}
\hline \multirow[b]{2}{*}{ Location } & \multirow{2}{*}{$\begin{array}{l}\text { RS prevalence } \\
(\%)\end{array}$} & \multirow{2}{*}{$\begin{array}{l}\text { DC prevalence } \\
(\%)\end{array}$} & \multicolumn{3}{|c|}{$\begin{array}{l}\text { Disabilities in accordance to defined stroke } \\
\text { performance (\%) }\end{array}$} & \multirow{2}{*}{$\begin{array}{l}\text { Pain severity }{ }^{\mathrm{a}} \text { throughout } \\
\text { serve performance }\end{array}$} \\
\hline & & & $\mathrm{FH}$ & $\mathrm{BH}$ & Serve & \\
\hline Shoulder & 32 & 44 & 50 & 11 & 87 & $4.00 \pm 3.25$ \\
\hline Hand/wrist & 25 & 33 & 75 & 54 & 28 & $2.50 \pm 2.73$ \\
\hline Elbow & 19 & 0 & 50 & II & 75 & $3.95 \pm 3.12$ \\
\hline
\end{tabular}

BH: backhand; DC: Davis Cup players; FH: forehand; RS: regional squad players. $p>0.05$ for analysis between DC and RS.

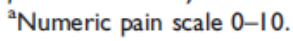




\section{DISCUSSION}

The main aim of this study was to examine athletic performance, training characteristics, and orthopedic status of junior DC in comparison to their peers (RS). The present results (1) show a high physical performance level in DC, notably in upper body power and strength, (2) underline the need for high training volumes to compete at a high level, and (3) reveal moderate to high injury prevalence in both DC and RS with no differences between performance levels.

\section{Training characteristics}

The data obtained reflect that players devote a great amount of time to improving their tennis performance throughout training interventions. Junior DC start playing tennis at a young age (6.4 \pm 1.0 years) and spend $22.7( \pm 6.8) \mathrm{h} / \mathrm{wk}$ for total training workout (tennis training and physical training). Because of the predominance of techniques and tactics in tennis, ${ }^{4}$ training priority is focused on the improvement of these skills with an average of $15.1 \mathrm{~h} / \mathrm{wk}$, while 7.6 $\mathrm{h} / \mathrm{wk}$ are spent for improvements of athletic performance. These data differ significantly in comparison to the training volume of the RS (Table 3), thus supporting the idea that high training volumes are necessary to compete at a high performance level. This fact is also reflected by the high correlation $(r=-0.78, p<0.05)$ observed between the total training volume and player's ranking position (Table 4). However, comparing these findings to the previous research is difficult since data on training characteristics in tennis do not receive much attention. Although the importance of intervention programs has not been questioned, there is less information about training characteristics compared to other sports, i.e., endurance-based sports. ${ }^{28,29}$ However, a few studies reported total training volumes, not evaluating a separate physical training. In adult elite tennis players (age $21.4 \pm 2.6$ years), Hornery et al. ${ }^{30}$ found a total training workload of $32 \mathrm{~h} / \mathrm{wk}$ during out of competition phases. In the investigation by SanchezMunoz et al., ${ }^{31} 23.2 \mathrm{~h} /$ week of training volume were recorded in elite male junior players (age $16.2 \pm 0.4$ years); the sample and results are in agreement with our findings in DC. Furthermore, training data of $D C$ are in line with the recommendation of the International Tennis Federation (ITF) to spend 15- $20 \mathrm{~h} / \mathrm{wk}$ on technical and tactical skills. ${ }^{9}$ Consequently, due to the fact that high training volumes seem to be indispensable for competing on an elite level even at a young age, training interventions must be organized as efficiently as possible to achieve an optimum cost-benefit ratio. ${ }^{10,15}$ Taking into account the abovementioned distribution of limiting performance factors (i.e., predominance of techniques and tactics), ${ }^{4}$ the application of specific diagnostics, notably of physical parameters, helps to design individualized training programs according to the respective needs, thus leading to a minimized training volume focused on fitness training thereby saving time for tennis-specific training. ${ }^{10,15}$

Correlation analysis between training volume and the players' age refers to an increased importance of physical training in older players (Table 4). While the volume of tennis training (i.e., techniques and tactics) is at a high level also in young players, physical training volume is 
enhanced in older ones. Consequently, and not surprisingly, there is also a positive moderate correlation between total training volume and age, as well as a high correlation between the ratio of tennis training and physical training and the age of players (Table 4). This might be due to fundamental changes in the biological system (i.e., hormone status) during and after maturity where some physical parameters (i.e., strength) are more likely to be enhanced. ${ }^{32}$ For example, with increasing age (11-15 with girls and 13-17 with boys), the influence of the strength region is increased through hormone distribution (testosterone and estrogen) and resultant muscular growth. $^{32}$ Nevertheless, interindividual variation has to be considered since the physical development of athletes in particular differs during the process of maturation (i.e., retardation and acceleration), independent of age. ${ }^{17,33}$ We suggest that the interindividual stage of maturation, which is reflected by our results of estimated age from/to peak height velocity ranging from -0.67 to +3.9 years, could also be one reason impeding general training guidelines and recommendations for physical training volume.

\section{Athletic performance}

In spite of the limited training time for physical training, data obtained for physical fitness indicate a moderate to high athletic performance level in junior DC according to norm values established by Fernandez- Fernandez et al. ${ }^{15}$ and Ulbricht et al. ${ }^{10}$ The qualities of the upper body strength and power-related characteristics (i.e., MBT and serve velocity) especially have to be highlighted with percentile values up to $85 \%$; this data differed significantly when compared to RS (Table 2). In this regard, results are in line with previous research reporting differences in physical performance measures between athletes with different performance levels in soccer players ${ }^{34,35}$ In agreement with Ulbricht et al., ${ }^{8}$ analyzing the effect of performance level in tennis players, results reinforce that players require well-developed physical fitness for competing on elite levels, and it is reasonable to assume that the qualities of upper body power and strength are one of the determining factors in tennis performance as supported by previous research. 8,36,37 Therefore, greater upper body power allows for the chance to improve tennis performance with higher stroke velocities. Since the modern game becomes faster, with the tennis serve being the most powerful and potentially dominant shot that influences the match results in the game of tennis, the implementation of high-serve velocities where $210 \mathrm{~km} / \mathrm{h}$ serves are common, has led to an advantage in winning the rally either through an ace or indirectly due to a defense situation of the opponent because of the given time pressure. ${ }^{1,2,38}$ In conclusion, the development and evaluation of upper body intervention programs for improving tennis performance is of great interest and utility. ${ }^{8}$

\section{Medical orthopedic status}

Results of medical orthopedic assessments refer to moderate and high injury prevalence in young athletes with no differences between performance levels, but with a tendency toward higher rates in DC (Table 5). Notwithstanding, comparisons are difficult since we are not aware 
of similar studies evaluating the effect of performance level on medical orthopedic status in elite junior tennis players. Concerning the effect of performance level, there is no consensus in the literature

whether there is an increased or decreased risk of injury with increasing skill level. Baxter-Jones et al., ${ }^{39}$ contrary to widely held opinion found, reported that while elite youth athletes do not appear to be at increased risk of injury, there is an increased risk of injury with increasing skill level in wrestling, as reported in a review of Emery. ${ }^{40}$ Further, Jayanthi et al. ${ }^{41}$ reported no differences in prevalence rates across different skill levels in recreational competition adult tennis players. We suppose that the tendency of higher injury rates in DC could occur due to the evidently higher demands in DC, particular in training volume and match participation (Table 3). This assumption is supported by previous research. In this regard, DiFori and colleagues ${ }^{42}$ summarized that the volume and intensity of training is strongly related to overuse injury risk.

With respect to an entire tennis career, the highest frequencies of MS are observed in the upper (i.e., shoulder with $67 \%$ in DC and 50\% in RS) and lower extremities (i.e., knee with $79 \%$ in DC and 54\% in RS), and also in the lower back (Table 5). These findings are in line with previous research. ${ }^{43-46}$ Epidemiologic studies evaluating tennis injuries reported that the lower and upper extremities are the body areas where injuries occur most frequently, with the shoulder, elbow, and knee being the most widely involved joints. ${ }^{44}$ In agreement with this, Priest and $\mathrm{Nagel}^{47}$ recorded that over $50 \%$ of the world's best tennis players had experienced shoulder symptoms during their career, mostly secondary to overuse injuries with muscle imbalances being a risk factor for developing disorders. ${ }^{14,48}$ For prevention strategies and performance enhancement, it is of great importance to identify and monitor these predisposed body areas so that prescribed limitations can be considered by coaches, conditioning professionals, and physiotherapists. ${ }^{44,46}$

Concerning the 12-month prevalence of MS of the upper extremities, results indicate that nearly $55 \%$ of athletes had at least one disability in this body region during the last year. Shoulder injuries (with values up to $44 \%$ ) were the most common, followed by injuries to the hand/wrist (33\%) and elbow (19\%) (Table 6). The assumption that shoulder pain and injuries are often related to the serve is reported by many authors ${ }^{13,14,49}$ and confirmed by our results, which indicate that $87 \%$ of the players with shoulder disabilities throughout the last 12 months have discomforts notably during serve performance and less during forehand (50\%) and backhand strokes (11\%). Moreover, the highest pain scores for pain severity during the tennis serve is related to the shoulder (4.00) followed by the elbow (3.95) and wrist (2.50) (Table 6). The actual high injury rate of the upper extremities, especially of the shoulder and in relation to the serve motion, could be explained by the strenuous repetitive forces during stroke production. ${ }^{13}$ Serve performance in particular generates a high load on tennis players' shoulders, ${ }^{14}$ and in addition to the shoulders' natural hypermobility and the excessive laxity of the glenohumeral joint, ${ }^{44}$ make the joints prone to injury. Johnson and $\mathrm{McHugh}^{13}$ emphasized that the shoulder plays an 
essential role in the kinetic chain to transfer the forces to the hand and the racket. The serve inherently requires repetitive powerful concentric internal shoulder rotation for power generation followed by eccentric forces to the external rotators to decelerate the overhead arm motion. ${ }^{44}$ Rotation velocities of $2420^{\circ} / \mathrm{s}$ (internal rotation) ${ }^{50}$ and large range of motion demands, especially in external rotation during the cocking phase, intensify the high stress on the serving shoulder. ${ }^{13}$ Taking the high repetitive nature of this stroke into consideration, only an adequate service technique and optimal strength and conditioning status for stabilizing the shoulder joint may prevent injuries, since improper serve techniques could result in increased loading of the upper limb joints. ${ }^{14,44,51}$

\section{CONCLUSION}

Due to the evolution of tennis over the last years from a preliminary technical sport to the explosive sport it is today, tennis has become increasingly dynamic and faster, with considerably high demands on young athletes to compete at an elite level. ${ }^{1,4}$ This is reflected in our results from analyzing athletic performance, training characteristics, and medical status in highperformance youth tennis. Results obtained in the present study indicate a higher physical performance level, especially in upper body power and strength (i.e., serve velocity, MBT, and grip strength) as well as higher training volumes (i.e., technique and tactics and physical conditioning) with differences of up to $8 \mathrm{~h} / \mathrm{wk}$ in junior DC. The observed differences in athletic performance between elite players and RS highlight the remarkable role of upper body power and strength in adolescent tennis. In this regard, we recommend upper body intervention programs to enhance performance levels due to the important role of serve performance in the modern tennis game. Moreover, there are moderate to high injury prevalences in DC and RS. The highest prevalence of MS was found in the body regions of the knee and shoulder. The high demands (i.e., scope with high physical stress, high training volume, and full tournament schedule) of successful participation in high-level youth tennis make it a challenge for coaches to have a player competing on the elite level with a low risk of injury. This has to be considered by coaches in planning their intervention programs: training interventions must be individualized according to the athlete's needs and limitations with respect to efficiency and saving time. ${ }^{10}$ Therefore, specific diagnostics are recommended at least twice a year (i.e., physical fitness tests). In addition, more effort is needed to develop training prescriptions for prevention strategies. The implementation of a high-quality tennis-specific prevention program (e.g., strengthening the external rotator for prevention of shoulder injuries which are due to serve performance) during training is required, as it may lessen the severity of overload injuries and enhance a player's performance. ${ }^{44,46}$ 


\section{Acknowledgements}

The authors thank all the athletes for participating in the study.

\section{REFERENCES}

1. Kovacs M. Tennis physiology: training the competitive athlete. Sports Med 2007; 37: 189-198.

2. Gillet $E$, Leroy $D$, Thouvarecq $R$, et al. $A$ notational analysis of elite tennis serve and serve-return strategies on slow surface. J Strength Cond Res 2009; 23: 532-539.

3. Reid M and Schneiker K. Strength and conditioning in tennis: current research and practice. J Sci Med Sport 2008; 11: 248-256.

4. Smekal G, Von Duvillard SP, Rihacek C, et al. A physiological profile of tennis match play. Med Sci Sports Exerc 2001; 33: 999-1005.

5. Fernandez-Fernandez J, Sanz-Rivas D. and Mendez-Villanueva A. A review of the activity profile and physiological demands of tennis match play. Strength Cond 2009; 31: 15-26.

6. Fernandez-Fernandez J, Ellenbecker TS, Sanz-Rivas D, et al. Effects of a 6-week junior tennis conditioning program on serve velocity. J Sport Sci Med 2013; 12: 232-239.

7. Girard $O$ and Millet GP. Physical determinants of tennis performance in competitive teenage players. J Strength Cond Res 2009; 23: 1867-1872.

8. Ulbricht A, Fernandez-Fernandez J, Mendez-Villanueva A, et al. Impact of fitness characteristics on tennis performance in elite junior tennis players. J Strength Cond Res. Epub ahead of print April 2016. DOI: $10.1519 /$ JSC.0000000000001267.

9. Crespo M and Miley D. ITF advanced coaches manual. London: ITF, 1998.

10. Ulbricht A, Fernandez-Fernandez J and Ferrauti A. Conception for fitness testing and individualized training programs in the German tennis federation. Sports Orthopaedics and Traumatology 2013; 29: 180-192.

11. Abrams GD, Sheets $A L$, Andriacchi TP, et al. Review of tennis serve motion analysis and the biomechanics of three serve types with implications for injury. Sports Biomech 2011; 10: 378-390.

12. Ferrauti A, Fernandez-Fernandez J, Klapsing GM, et al. Diagnostic of footwork characteristics and running speed demands in tennis on different ground surfaces. Sports Orthopaedics and Traumatology 2013; 29: 172-179.

13. Johnson C and McHugh M. Performance demands of professional male tennis players. Br J Sports Med 2006; 40: 696-699.

14. Martin $C$, Bideau $M$, Ropars $M$, et al. Upper limb joint kinematic analysis during tennis serve: Assessment of competitive level on efficiency and injury risks. Scand J Med Sci Sports. Epub ahead of print 7 January 2013. Doi: 10.1111/sms.12043. 
15. Fernandez-Fernandez J, Ulbricht $A$ and Ferrauti A. Fitness testing of tennis players: How valuable is it? Br J Sports Med 2014; 48: i22-i31.

16. Roetert EP, Piorkowski PA, Woods RB, et al. Establishing percentiles for junior tennis players based on physical fitness testing results. Clin Sports Med 1995; 14: 1-21.

17. Mirwald RL, Baxter-Jones AD, Bailey DA, et al. An assessment of maturity from anthropometric measurements. Med Sci Sports Exerc 2002; 34: 689-694.

18. Baxter-Jones ADG and Sherar LB. Growth and maturation. In: Armstrong N (ed) Paediatric Exercise Physiology. Advances in Sport and Exercise Science Series. Churchill Livingston: Elsevier, 2007, pp. 126.

19. Mendez-Villanueva A, Buchheit $\mathrm{M}$, Kuitunen $\mathrm{S}$, et al. Is the relationship between sprinting and maximal aerobic speeds in young soccer players affected by maturation? Pediatr Exerc Sci 2010; 22: 497-510.

20. Innes E. Handgrip strength testing: a review of the literature. Aust Occup Ther J 1999; 46: 120-140.

21. Esco MR, Olson MS and Williford $H$. Relationship of push-ups and sit-ups tests to selected anthropometric variables and performance results: A multiple regression study. J Strength Cond Res 2008; 22: 1862-1868.

22. Bosco $\mathrm{C}$, Mognoni $\mathrm{P}$ and Luhtanen $\mathrm{P}$. Relationship between isokinetic performance and ballistic movement. Eur J Appl Physiol Occup Physiol 1983; 51: 357-364.

23. Ferrauti A, Kinner $\mathrm{V}$ and Fernandez-Fernandez J. The Hit \& Turn Tennis Test: an acoustically controlled endurance test for tennis players. J Sports Sci 2011; 29: 485-494.

24. Cook G, Burton $L$ and Hoogenboom B. Pre-participation screening: the use of fundamental movements as an assessment of function - part 2. N Am J Sports Phys Ther_2006; 1: 132-139.

25. Kuorinka I, Jonsson B, Kilbom $\AA$, et al. Standardized Nordic questionnaires for the analysis of musculoskeletal symptoms. Appl Ergon 1987; 18: 233-237.

26. Von Korff M, Ormel J, Keefe FJ, et al. Grading the severity of chronic pain. Pain 1992; 50: 133-49.

27. Cohen J. Statistical power analysis for the behavioral-sciences. Percept Mot Skills 1988; 67: 10071007.

28. Billat V, Lepretre PM, Heugas AM, et al. Training and bioenergetic characteristics in elite male and female Kenyan runners. Med Sci Sports Exerc 2003; 35: 297-304.

29. Esteve-Lanao J, San Juan AF, Earnest $C P$, et al. How do endurance runners actually train? Relationship with competition performance. Med Sci Sports Exerc 2005; 37: 496-504.

30. Hornery D, Farrow D, Mujika I, et al. An integrated physiological and performance profile of professional tennis. Br J Sports Med 2007; 41: 531-536.

31. Sanchez-Munoz C, Sanz D and Zabala M. Anthropometric characteristics, body composition and somatotype of elite junior tennis players. Br J Sports Med 2007; 41: 793-799. 
32. Grosser M and Schönborn R. Competitive tennis for young players. Oxford: Meyer \& Meyer, 2002.

33. Malina RM, Bouchard C and Bar-Or O. Growth, maturation, and physical activity, Leeds UK: Human Kinetics Publishers, 2004.

34. Gravina L, Gil SM, Ruiz F, et al. Anthropometric and physiological differences between first team and reserve soccer players aged 10-14 years at the beginning and end of the season. J Strength Cond Res 2008; 22: 1308-1314.

35. Le Gall F, Carling C, Williams M, et al. Anthropometric and fitness characteristics of international, professional and amateur male graduate soccer players from an elite youth academy. J Sci Med Sport 2010; 13: 90-95.

36. Cohen DB, Mont MA, Campbell KR, et al. Upper extremity physical factors affecting tennis serve velocity. Am J Sports Med 1994; 22: 746-750.

37. Perry $A C$, Wang $X$, Feldman $B B$, et al. Can laboratory-based tennis profiles predict field tests of tennis performance? J Strength Cond Res 2004; 18: 136-143.

38. Kovacs MS and Ellenbecker TS. A performance evaluation of the tennis serve: implications for strength, speed, power, and flexibility training. Strength Cond 2011; 33: 22-30.

39. Pluim BM, Staal LB, Windler GE, et al. Tennis injuries: occurrence, aetiology, and prevention. Br J Sports Med 2006; 40: 415-423.

40. Baxter-Jones AD, Mafulli N and Helms P. Low injury rates in elite athletes. Arch Dis Child 1993; 68: 130-132.

41. Emery CA. Risk factors for injury in child and adolescent sport: a systematic review of the literature. Clin J Sport Med 2003; 13: 256-268.

42. Jayanthi $\mathrm{N}$, Sallay $\mathrm{Pl}$, Hunker $\mathrm{P}$, et al. Skill-level related injuries in recreational competition tennis players. J Med Sci Tennis 2005; 10: 12-15.

43. Difori J, Benjamin H, Brenner J, et al. Overuse injuries and burnout in youth sports: a position statement from the American medical society for sports medicine. Clin J Sport Med 2014; 24: 3-20.

44. Ellenbecker TS, Pluim B, Vivier $S$, et al. Common injuries in tennis players: exercises to address muscular imbalances and reduce injury risk. Strength Cond 2009; 31: 50-58.

45. Perkins RH and Davis D. Musculoskeletal injuries in tennis. Phys Med Rehabil Clin N Am 2006; 17: 609-631.

46. Pluim BM, Loeffen FGJ, Clarsen B, et al. A one-season prospective study of injuries and illness in elite junior tennis. Scand J Med Sci Sports 2015. Epub ahead of print 5 May 2015. Doi: 10.1111/sms.12471.

47. Priest JD and Nagel DA. Tennis shoulder. Am J Sports Med 1976; 4: 28-42.

48. Chandler TJ, Kibler WB, Stracener EC, et al. Shoulder strength power, and endurance in college tennis players. Am J Sports Med 1992; 20: 455-458. 
49. Elliott B, Fleisig $G$, Nicholls $R$, et al. Technique effects on upper limb loading in the tennis serve. J Sci Med Sport 2003; 6: 76-87.

50. Fleisig G, Nicholls R, Elliott $B$, et al. Kinematics used by world class tennis players to produce highvelocity serves. Sports Biomech 2003; 2: 51-64.

51. Kibler WB. Biomechanical analysis of the shoulder during tennis activities. Clin Sports Med 1995; 14: 79-85. 